\title{
SISTEM PENUNJANG KEPUTUSAN KRITERIA BEASISWA MENGGUNAKAN RULE BASED DAN FORWARD CHAINING
}

\author{
Nurul Azizaturrizqiyah ${ }^{1)}$ Munawarah ${ }^{2)}$ Tholib Hariono $^{3)}$ \\ 1) e-mail : nurulazizaturrizqiyah19@gmail.com \\ ${ }^{2)}$ e-mail : munawarahmira@yahoo.com \\ ${ }^{3)}$ e-mail : harionotholib@gmail.com
}

\begin{abstract}
It is known in the selection of the scholarship will certainly experience difficulties because of the many criteria for scholarship applicants and the number of criteria used to determine the grantee's decision as expected. Therefore the need for a system of decisionmakers to take into account all the criteria that support decision making by using rule-based and forward chaining, because the rule-based and forward chaining will implement a counting system for certain that the admin just entering data and will gain value in accordance with the criteria.

In this study, the author tries to analyze the main points of the discussion and the results are intended to develop information systems that can be used in AMIK Jombang. System decision makers have preferred to build a decision matrix, decision making matrix is normalized, weighted normalized decision making matrix, determine the positive and negative ideal solution, calculate separation, calculate the relative proximity to the positive ideal solution, rank the alternatives. The final result of the data sorting recipients.
\end{abstract}

Keywords: scholarships, rule based dan forward chaining 


\section{Pendahuluan}

\subsection{Latar Belakang}

Beasiswa adalah dukungan biaya Pendidikan yang diberikan kepada Mahasiswa untuk mengikuti dan/atau menyelesaikan Pendidikan Tinggi berdasarkan pertimbangan utama prestasi dan/atau potensi akademik. Sedangkan "bantuan biaya pendidikan" adalah dukungan biaya Pendidikan yang diberikan kepada Mahasiswa untuk mengikuti dan/atau menyelesaikan Pendidikan Tinggi berdasarkan pertimbangan utama keterbatasan kemampuan ekonomi. (Direktorat Jenderal Pembelajaran dan Kemahasiswaan, 2015). Dengan demikian beasiswa harus diberikan kepada penerima yang layak dan pantas untuk mendapatkannya. Akan tetapi, dalam melakukan seleksi beasiswa tersebut tentu akan mengalami kesulitan karena banyaknya kriteria pelamar beasiswa dan banyaknya kriteria yang digunakan untuk menentukan keputusan penerima beasiswa yang sesuai dengan yang diharapkan. Untuk itu diperlukannya suatu sistem pengambil keputusan yang dapat memperhitungkan segala kriteria yang mendukung pengambilan keputusan. Dalam hal ini penulis menggunakan system pengambil keputusan dengan menggunakan rule based dan forward chaining.

\subsection{Metodologi Penelitian}

Metode penelitian yang dilakukan penulis dalam penelitian ini yaitu dengan menggunakan metode penelitian R \& D (Research and Development). Adapun cara penelitian yang dilakukan penulis dalam penelitian ini dengan menggunakan metode penelitian R \& D, adalah sebagai berikut :

1. Penelitian dan Penggunaan Data

Pada tahap ini penulis melakukan analisa persiapan kebutuhan penelitian seperti tinjauan pustaka, aturan - aturan penulis serta meode yang akan digunakan yang berkaitan dengan penelitian, antara lain :

$>$ Study Pustaka

Dengan mengumpulkan dan mempelajari lieratur yang berkaitan dengan peramalan penjualan buku dengan metode TrendMoment. Sumber literature berupa buku teks, paper, jurnal, karya ilmiah dan situs - situs penunjang ainya.

$>$ Pengumpulan Data

Data yang dikumpulkan berupa hasil wawancara dan data penjualan buku selama 24 bulan terakhir.

\section{Landasan Teori}

\subsection{Beasiswa}

Beasiswa adalah dukungan biaya Pendidikan yang diberikan kepada Mahasiswa untuk mengikuti atau menyelesaikan Pendidikan Tinggi berdasarkan pertimbangan utama prestasi atau potensi akademik. Sedangkan "bantuan biaya pendidikan" adalah dukungan biaya Pendidikan yang diberikan kepada Mahasiswa untuk mengikuti dan/atau menyelesaikan Pendidikan Tinggi berdasarkan pertimbangan utama keterbatasan kemampuan ekonomi.

\subsection{Rule Based dan Forward Chaining}

Sistem berbasis aturan (rule-based system) adalah sebuah program yang menggunakan aturan IF-THEN. Model ini berbeda dengan pemrograman konvensional, misalnya rule tidak harus berada pada urutan tertentu.

Sistem berbasis aturan (rule-based system) menggunakan Modus Ponens sebagai dasar untuk memanipulasi aturan, yaitu: 
fakta A benar, dan operasi A $\rightarrow$ B benar, maka fakta B adalah benar

Dengan menggunakan teknik searching yang telah didefinisikan dalam Sistem Berbasis Aturan diatas dan penyesuaian pola (pattern matching), sistem berbasis aturan melakukan proses reasoning mulai dari fakta awal sampai menuju pada kesimpulan. Dalam proses ini mungkin akan dihasilkan fakta-fakta baru menuju pada penyelesaian masalah. Jadi dapat disimpulkan bahwa proses penyelesaian masalah pada sistem berbasis aturan adalah menciptakan sederet fakta-fakta baru yang merupakan hasil dari sederetan proses inferensi sehingga membentuk semacam jalur antara definisi masalah menuju pada solusi masalah. Deretan proses inferensi tersebut adalah inference chain.

1. Jika hanya rule 1 (tanpa rule 2 dan rule 3), sistem berbasis pengetahuan tidak berarti apa-apa.

2. Karena itu sebuah sistem berbasis pengetahuan harus terdiri atas sekelompok aturan yang membentuk rangkaian aturan rule chain.

3. Fakta didefisinikan sebagai statemen yang dianggap benar.

4. Maka proses inferensi melihat fakta-fakta dari premis pada rule 1 dan rule 2 sebagai dasar untuk menghasilkan fakta baru.

Selanjutnya proses inferensi melihat bahwa kedua fakta ini sesuai dengan premis pada rule 3 , maka akan dihasilkan fakta baru lagi.

Dalam forward chaining, proses inferensi dimulai dari seperangkat data yang ada menuju ke kesimpulan. Pada proses ini akan dilakukan pengecekan terhadap setiap rule untuk melihat apakah data yang sedang diobservasi tersebut memenuhi premis dari rule tersebut. Apabila memenuhi, maka rule akan dieksekusi untuk menghasilkan fakta baru yang mungkin akan digunakan oleh rule yang lain. Proses pengecekan rule ini disebut sebagai rule interpretation. Pada sistem berbasis pengetahuan, rule interpretation (interpretasi rule) dilakukan oleh inference engine. Proses interpretasi rule ini merupakan proses berulang seperti terlihat dalam Gambar 2.2.

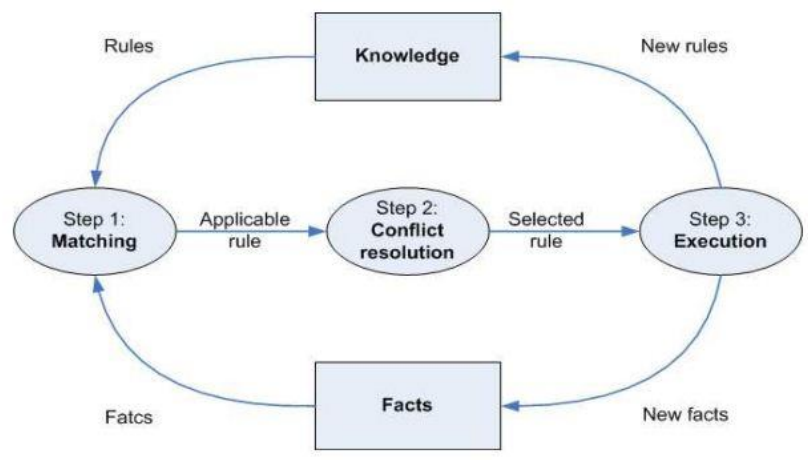

Gambar 2.2. Proses Interpretasi Rule

Fungsi masing-masing step untuk gambar di atas dijelaskan sebagai berikut:

1. Matching. Pada step ini, setiap rule yang ada pada basis pengetahuan dibandingkan dengan fakta-fakta yang diketahui untuk mencari rule mana yang memenuhi (istilah 'memenuhi' berarti: situasi, premis, atau antecedent bernilai benar).

2. Conflict Resolution. Pada langkah pertama sangat mungkin dihasilkan suatu kondisi dimana beberapa rule dipenuhi. 
3. Conflict Resolution bertugas untuk mencari rule mana yang memiliki prioritas tertinggi yang berpotensi untuk dieksekusi.

Execution. Langkah terakhir dari proses forward chaining adalah eksekusi (firing) dari rule. Proses ini menghasilkan dua kemungkinan, yaitu: fakta baru diturunkan dan ditambahkah fact base atau rule baru dihasilkan dan ditambahkan ke knowledge base.

\section{Analisis dan Perancangan Sistem}

\subsection{Analisis Kelemahan Sistem}

Akademi Manajemen Informatika dan Komputer (AMIK) Jombang merupakan perguruan tinggi yang bergerak dalam bidang pendidikan yang tentu jika dalam pengambil keputusan beasiswa masih menggunakan sistem manual tentu banyak memiliki kelemahan, diantaranya antara lain:

1. Pengumpulan data-data pengajuan beasiswa akan membutuhkan berkas dan tempat penyimpanan yang banyak

2. Sulit dalam mencari data-data yang akan dibutuhkan untuk menyeleksi karena harus mencari di banyak berkas

3. Pengajuan beasiswa yang saat ini masih manual

4. Sulit dan lambat dalam menyeleksi siapa yang pantas mendapatkan beasiswa, baik beasiswa BBM maupun PPA

5. Sistem yang masih kurang akurat

6. Lambatnya dalam mengambil sebuah keputusan, karena tidak didukung oleh sistem informasi yang baik

\subsection{Analisis Kebutuhan Sistem}

Dari data kelemahan dalam sistem sebelumnya, maka perlu dibutuhkan sebuah sistem baru untuk menjawab kelemahan-kelemahan dalam sistem lama tersebut. Dibutuhkan sebuah sistem yang memudahkan dalam pengambilan keputusan untuk menentukan beasiswa dengan menggunakan rule based dan forward chaining. Untuk lebih jelasnya, akan dijelaskan kebutuhan sistem dalam menyelesaikan masalah atau kelemahan sistem yang lama, yaitu:

1. Untuk menangani masalah mulai dari pengumpulan data, penyeleksian data beasiswa, pengambilan keputusan siapa yang berhak menerima beasiswa, serta untuk memperoleh informasi yang cepat akurat mengenai informasi beasiswa maka dibuatkan Sistem Informasi Pengambil Keputusan untuk Menentukan Beasiswa Menggunakan Rule Based dan Forward Chaining. Sistem ini akan menyelesaikan masalah atau kelemahan dalam sistem yang lama, misalnya:

a. Pengumpulan data yang sangat banyak akan tersimpan semua dalam database. Yang database tersebut tentu saja akan tersimpan sehingga memudahkan admin untuk mengelolah data pengaju beasiswa

b. Penyeleksian data yang cepat dan akurat, karena data yang tersimpan dalam database tadi diolah menjadi sebuah informasi yang diperintah oleh bahasa pemrograman PHP dan menggunakan rule based dan forward chaining

c. Pembuatan informasi beasiswa yang mudah dan cepat karena data-data yang tersimpan dalam database akan diolah sedemikian rupa oleh perintah Bahasa Pemrograman PHP yang akan menjadi informasi beasiswa yang dibutuhkan dalam bentuk informasi yang akan ditampilkan ke website

d. Akan cepat mengambil sebuah keputusan karena sistemnya terkomputerisasi dengan mudah mengakses sistem yang dibutuhkan.

\section{A. Kebutuhan Perangkat Keras}

Kebutuhan perangkat keras untuk menjalankan sistem ini adalah: 
1. PC/Laptop dengan spesifikasi minimal Harddisk 32 GB, Processor Pentium IV, RAM sebesar $512 \mathrm{MB}$.

2. Wifi untuk akses internet.

3. Printer, untuk mencetak dokumen jika diperlukan dokumen cetaknya.

\section{B. Kebutuhan Perangkat Lunak}

Dalam pembuatan sistem informasi pengambil keputusan untuk menentukan beasiswa ini membutuhkan 4 perangkat lunak yang sudah dijelaskan di atas yaitu:

1. PHP sebagai Perangkat lunak Bahasa Pemrograman

2. Perangkat lunak XAMPP sebagai web server

3. MySQL sebagai perangkat lunak Database

4. Sistem Operasi Windows 7 sebagai sistem operasinya

5. PhpMyAdmin sebagai editor database

6. Mozilla Firefox sebagai web browser

7. Adobe Dreamweaver sebagai media pembuatan pemrograman berbasis web

8. Microsoft Office Visio sebagai graphic design editor bagan alir

\section{Kebutuhan Informasi}

Informasi yang dihasilkan oleh Aplikasi ini antara lain:

1. Penyeleksian yang terkomputerisasi

2. Informasi beasiswa secara online

3. Dokumen beasiswa (berupa softcopy).

\section{Kebutuhan Pengguna (user)}

Aplikasi ini nantinya akan dioperasikan oleh 3 jenis user. User sebagai mahasiswa memiliki username dan password masing-masing kemudian user umum yang hanya melihat informasi yang ada di home dan yang terakhir user sebagai admin yang menginputkan data. Setiap Jenis user memiliki wewenang, tugas dan apa saja yang bisa dilakukan dalam aplikasi ini yang berbeda- beda. Jenis user itu antara lain:

1. Admin: mempunyai tugas untuk menginputkan data, mengecek dan memproses data.

2. User sebagai mahasiswa: memiliki username dan password masing-masing yang nanti bisa mendaftarkan beasiswa.

3. User umum: hanya melihat informası yang ada pada menu home saja

\subsection{Perancangan Sistem}

Pada tahapan desain ini penulis akan merancang sistem guna menyeleseaikan masalah yang ada. Adapun rancangan sistem yang penulis buat meliputi rancangan Data Flow Diagram (DFD) dan alur system (Flowchar). 
a. Flowchart

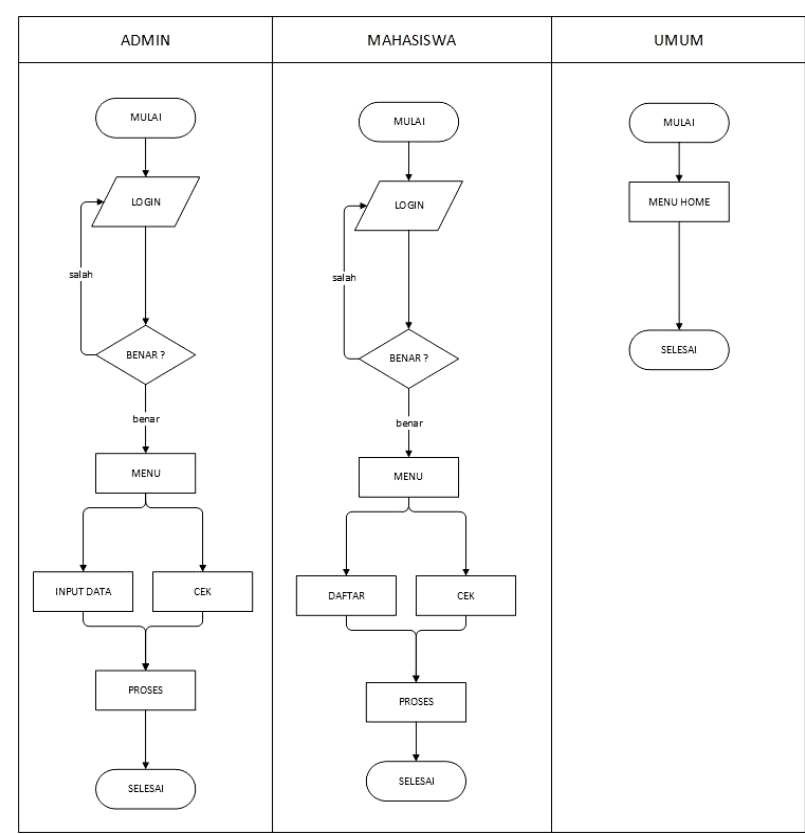

Gambar 3.1 Flowchart

\subsection{Perancangan Basis Data}

Dalam perancangan database dijelaskan beberapa tabel dalam database tersebut yang dibutuhkan dalam membentuk rancangan Aplikasi peramalan Penjualan dengan metode Trendmoment, ada beberapa tabel yang secara umum diuraikan sebagai berikut:

1. Tabel Formulir

Tabel 3.1. Tabel Formulir

\begin{tabular}{|l|l|l|}
\hline Field Name & Type & Width \\
\hline NIM & Integer & 25 \\
\hline Nama_lengkap & Varchar & 200 \\
\hline Prodi & Varchar & 50 \\
\hline Jenis_kelamin & Varchar & 200 \\
\hline Jenis_beasiswa & Varchar & 20 \\
\hline IPK & Varchar & 10 \\
\hline Jumlah_saudara & Integer & 10 \\
\hline Pekerjaan_ortu & Varchar & 200 \\
\hline Penghasilan_ortu & Integer & 50 \\
\hline Id_upload & Integer & 30 \\
\hline Pengajuan_beasiswa & Varchar & 200 \\
\hline Aktif_kuliah & Varchar & 200 \\
\hline KTM & Varchar & 200 \\
\hline KTP & Varchar & 200 \\
\hline KK & Varchar & 200 \\
\hline SKPB_kelurahan & Varchar & 200 \\
\hline SKTM_kelurahan & Varchar & 200 \\
\hline Data_penghasilan_ortu & Varchar & 200 \\
\hline Piagam & Varchar & 200 \\
\hline Rekening_tabungan & Varchar & 200 \\
\hline KHS & Varchar & 200 \\
\hline KRS & Varchar & 200 \\
\hline Hasil & Varchar & 50 \\
\hline Status & Varchar & 100 \\
\hline & & \\
\hline
\end{tabular}


2. Tabel Rangking Penilaian

Tabel 3.2. Tabel Rangking Penilaian

\begin{tabular}{|l|l|l|}
\hline Field Name & Type & Width \\
\hline Id_rangking_ppa & Integer & 50 \\
\hline Batas_ppa & varchar & 50 \\
\hline Batas_bbp_ppa & varchar & 50 \\
\hline Batas_penerimaan_ppa & varchar & 50 \\
\hline Batas_penerimaan_bbp_ppa & varchar & 50 \\
\hline
\end{tabular}

\subsection{Perancangan Interface/Antar Muka}

Dalam pembahasan rancangan di atas, telah dijelaskan mengenai perancangan proses dan basis data sistem ini. Selanjutnya adalah pembahasan mengenai perancangan sistem berdasarkan tampilan program atau interface. Adapun perancangan interface yang akan dibahas oleh penulis, adalah sebagai berikut :

A. Design Aplikasi

1. Halaman Home

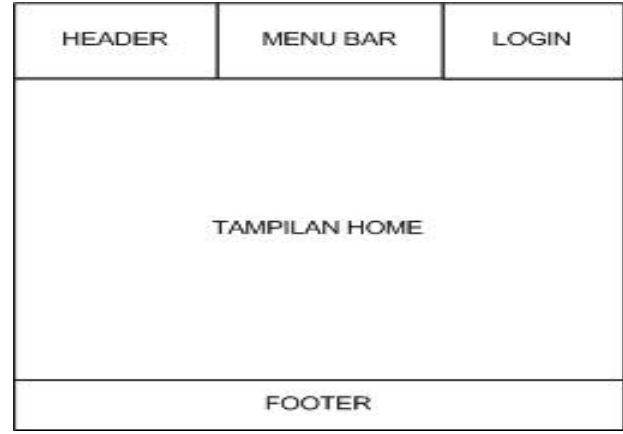

Gambar 3.2. Design Menu Utama

2. Menu Login

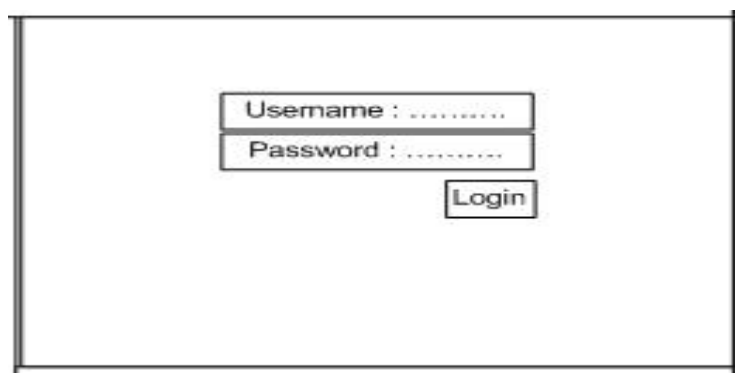

Gambar 3.3. Design Menu Login 
3. Dashboard Pendaftar

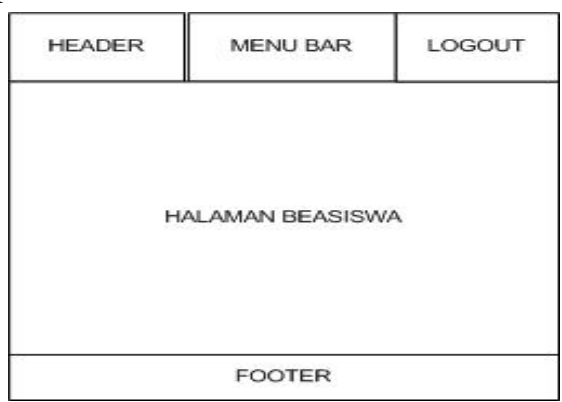

Gambar 3.4. Design dashboard pendaftar

\section{IMPLEMENTASI DAN PEMBAHASAN}

\subsection{Implementasi}

Sistem penunjang keputusan kriteria beasiswa menggunakan rule based dan forward chaining ini berbasis web, menggunakan bahasa pemrograman PHP dan database MySQL serta menggunakan metode rule based dan forward chaining. Dalam mengimplementasikan sistem ini, harus diterapkan atau diunggah pada hosting agar bisa diakses di internet.

\subsection{Pembahasan}

\subsubsection{Pembahasan Sistem}

A. Halaman Index Awal

Adalah halaman yang paling awal dari website ini.

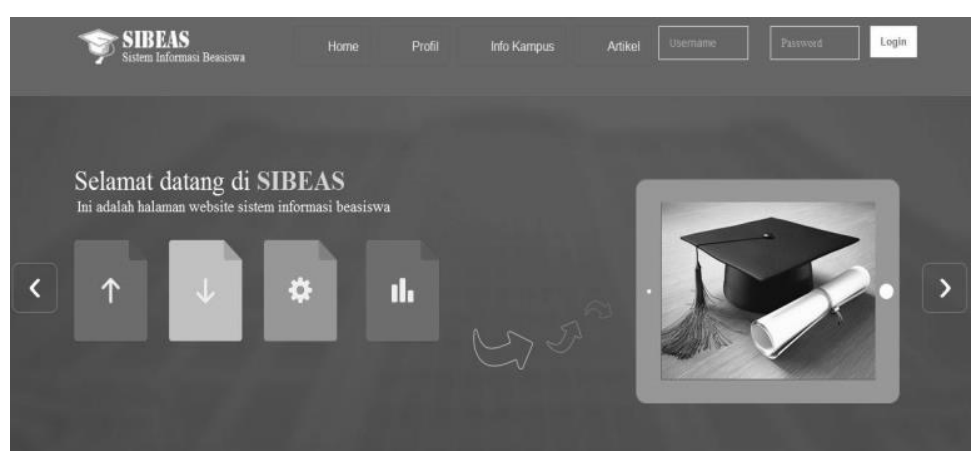

Gambar 4.1 Gambar Form Menu Login

B. Menu Login User (Pendaftar)

menu ini untuk mahasiswa yang memiliki usename dan password. Yang nantinya mahasiwa tersebut akan melakukan pendaftaran beasiswa.

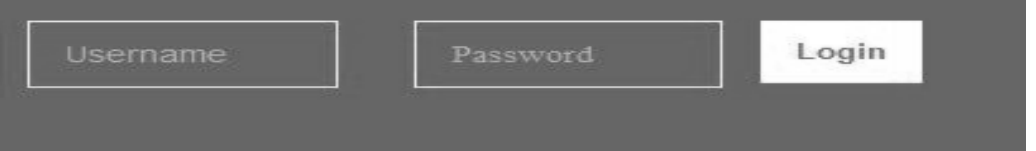

Gambar 4.2 From Menu Login User(Pendaftar) 


\section{Halaman Beranda Pendaftar}

Adalah halaman awal yang pertama kali tampil di berandapendaftar beasiswa yang nantinya akan ada tampilan sambutan untuk mahasiswa yang telah login.

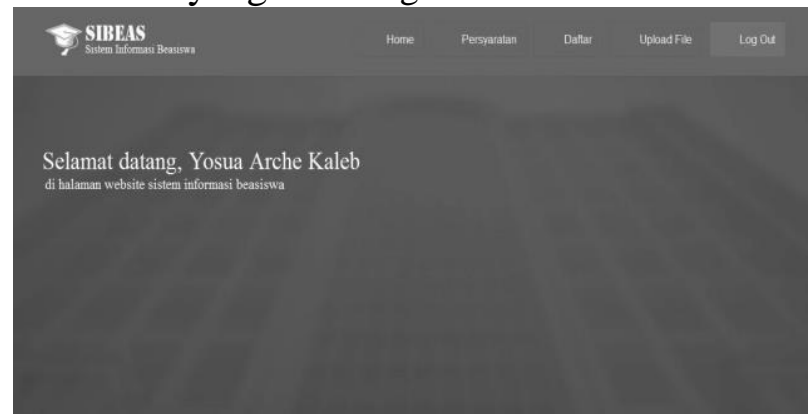

Gambar 4.3 Beranda Pendaftar

\section{Dashboard Admin}

Halaman home atau beranda admin adalah halaman awal yang pertama kali tampil di level admin.

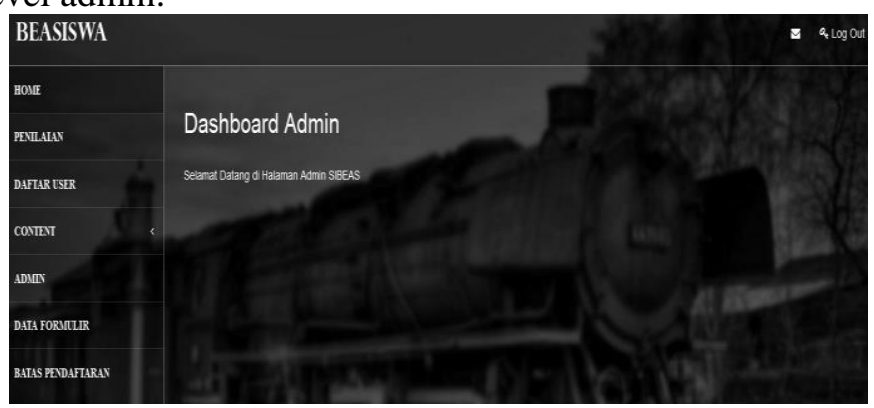

Gambar 4.4 Beranda Admin

\subsubsection{Analisis Hasil}

Berdasarkan hasil perhitungan kriteria penerima beasiswa, dapat diketahui dari data penilaian. Dalam perhitungan penerima beasiswa PPA, penulis menggunakan kriteria IPK yang tertinggi sesuai dengan kriteria yang ditentukan oleh DIKTI, dengan rinciannya:

Jika IPK >= 3.75 maka nilainya 100

Jika IPK > 3.50 maka nilainya 75

Jika IPK > 3.25 maka nilainya 50

Jika IPK $>3.00$ maka nilainya 25

Jika IPK $<3.00$ maka nilainya 5

Sedangkan untuk BBP-PPA menggunakan kriteria dari IPK dan penghasilan orang tua, berikut rinciannya:

IPK minimal 3.00

Penghasilan Orang Tua: - jika penghasilan $<1$ juta maka nilai100

- jika penghasilan 1-2 juta maka nilai 75

- jika penghasilan < 3 juta maka nilai 50

- jika penghasilan > 3 juta maka nilai 25

- jika penghasilan 4 juta keatas maka nilai 0 
Jadi, apabila ditambahkan antara IPK dan penghasilan orang tua maka berikut perhitungannya:

- jika IPK $>=3.75$ dan penghasilan orang tua $<1000000$ maka nilainya 100

- jika IPK $>=3.75$ dan penghasilan orang tua $<2000000$ maka nilainya 95

- jika IPK $>=3.75$ dan penghasilan orang tua $<3000000$ maka nilainya 90

- jika IPK $>=3.50$ dan penghasilan orang tua $<1000000$ maka nilainya 85

- jika IPK $>=3.50$ dan penghasilan orang tua $<2000000$ maka nilainya 80

- jika IPK $>=3.50$ dan penghasilan orang tua $<3000000$ maka nilainya 75

- jika IPK $>=3.25$ dan penghasilan orang tua $<1000000$ maka nilainya 70

- jika IPK $>=3.25$ dan penghasilan orang tua $<2000000$ maka nilainya 65

- jika IPK $>=3.25$ dan penghasilan orang tua $<3000000$ maka nilainya 60

- jika IPK $>=3.00$ dan penghasilan orang tua $<1000000$ maka nilainya 55

- jika IPK $>=3.00$ dan penghasilan orang tua $<2000000$ maka nilainya 50

- jika IPK >= 3.00 dan penghasilan orang tua $<3000000$ maka nilainya 45

Setelah melakukan perhitungan maka akan diketahui perkiraan hasil untuk penerimaan beasiswa yang nilainya sudah di globalkan dalam status yang menyatakan "LULUS" atau TIDAK LULUS"

Maksud status "LULUS" sendiri adalah dimana nilai yang di peroleh mahasiswa yang mengajukan beasiswa telah memenuhi standart yang di berikan oleh DIKTI.

Sedangkan status "TIDAK LULUS" jumlah nilai yang didapat masih dibawah standart kategori yang di berikan oleh DIKTI.

Dari data LULUS dan TIDAK LULUS diatas, maka data yang termasuk LULUS sudah otomatis menunjukkan urutan dari nilai tertinggi sampai paling rendah. Dalam hal ini, penerima beasiswa untuk PPA hanya diambil 7 orang sedangkan BBP-PPA hanya 5 orang saja.

\section{Penutup}

\subsection{Kesimpulan}

Penulis memberikan beberapa simpulan mengenai sistem ini, yang kiranya bisa menjadi sebuah bahasan dari semua pembaca dokumen skripsi ini.

1. Sistem informasi beasiswa ini dirancang dengan 3 user, dimana memiliki beberapa user pengguna. Diantaranya adalah user Admin, user umum, dan user mahasiswa. Tiap user memiliki fungsi dan peran masing-masing.

2. Dengan adanya sistem ini, dapat membantu proses pengambil keputusan untuk menentukan beasiswa dan mempermudahkan mahasiswa mengajukan beasiswa, dimana sebelumnya pengelolaan beasiswa bersifat manual beralih menjadi pengelolaan terkomputerisasi yang dirasa lebih banyak kelebihannya (lebih efisien, efisien waktu karena mudah diakses dimana saja dan kapan saja).

3. Sistem ini menggunakan rule based dan forward chaining untuk memudahkan perhitungan kriteria beasiswa dan untuk mempermudah dalam pengambilan sebuah keputusan untuk menentukan beasiswa.

\subsection{Saran}

Setelah dilakukan penelitian ini, disarankan:

1. Sebelum benar-benar menerapkan sistem ini, diadakan terlebih dahulu sebuah diklat, training atau pelatihan mengenai sistem ini, dengan tujuan agar para calon user mengenal dan mengerti akan proses penggunaan sistem agar tidak mengalami kesulitan dalam penerapan sistem kedepannya. 
2. Admin diharapkan mengelola secara baik sistem tersebut, karena kapan saja sistem ini sering diakses dan perubahan atau penambahan data yang dilakukan user bisa saja sering intensitasnya.

3. Sistem ini diharapkan memperhatikan keamanan. Dalam sistem ini, keamanan dapat direalisasikan dengan membatasi akses dengan pembagian hak akses. Seperti user umum yang hanya bisa mengakses menu home saja, tapi tidak bisa login ataupun mendaftar.

4. Harapannya pengembangan sistem terus dilakukan, agar kesalahan-kesalahan yang terjadi bisa diperbaiki dan saran-saran yang telah dikemukakan penulis pada poinpoin sebelumnya bisa tercapai dengan baik.

\section{DAFTAR PUSTAKA}

Benny Wijaya dan Maria Irmina Prasetiyowati. 2012. Rancang Bangun Sistem Pakar Pendiagnosa Penyakit Demam Typhoid dan Demam Berdarah Dengue dengan Metode Forward Chaining.

Kementrian Riset, Teknologi, dan Pendidikan Tinggi Koordinasi Perguruan Tinggi Swasta Wilayah VII. 2016. Pedoman Teknis Beasiswa dan Bantuan Biaya Pendidikan Peningkatan Prestasi Akademik Tahun 2016.

Fathansyah, Ir. 1999. Basis Data. CV. Informatika. Bandung.

Hoffer, Jeffrey A, Mary B. Prescott, dan Fred R.McFadden. 2002. Modern Database Management International Edition. Prentice Hall (Person Education), New Jersey.

Irawan Jusak. 2007. Buku Pegangan Kuliah Sistem Pakar. Sekolah Tinggi Manajemen Informatika \& Teknik Komputer Surabaya (STIKOM).

Jogiyanto HM. 1988. Analisa dan Desain Sistem Informasi. Andi Offset: Yogyakarta.

Jogiyanto HM. 2005. Analisis \& Desain Ed ke-III hal.795. Andi Offset: Yogyakarta.

Ladjamuddin B. Al-Bahra. 2006. Rekayasa Perangkat Lunak hal 225. cet-keII GRAHA ILMU. Yogyakarta.

McLeod, Jr, R. dan Schell G. 2004. Sistem Informasi Manajemen Edisi Delapan. PT. INDEKS, Jakarta.

Sunarfrihantono, Bimo, ST. 2002. PHP dan MySQL untuk Website. Yogyakarta: Andi Offset 